\title{
EXAMINING NON-LINEAR RELATIONSHIPS \\ BETWEEN HUMAN RESOURCE PRACTICES \\ AND MANUFACTURING PERFORMANCE
}

\author{
CLINT CHADWICK*
}

\begin{abstract}
One little-explored question concerning innovative human resources practices is how the intensity of their implementation affects their impact on establishment performance: is the relationship linear, or more complex? This analysis, using U.S. Census Bureau data for 1997 from a sample of 1,212 private sector manufacturing establishments, investigates the possibility of non-linearities in the relationship between establishment performance and six human resource practices. The author finds departures from linearity that are both statistically significant and substantively meaningful for four of the six practices. He concludes that linear estimations of these relationships could mislead theorists and result in faulty recommendations to practitioners.
\end{abstract}

$I^{1}$ n the growing subfield of Strategic $\mathrm{Hu}$ man Resource Management (SHRM), the basic contention that systems of human resource (HR) policies and practices can have strong relationships with organizational performance has drawn a compelling body of empirical support. Moving beyond this fundamental point, the next set of questions in SHRM research concerns the subtleties of these relationships with performance, including such issues as the specific causal mechanisms linking major constructs and the appropriate lag period for the effects of HR systems after their implementation. In this spirit, this paper targets the largely

*Clint Chadwick is an Assistant Professor of Labor and Industrial Relations at the University of Illinois at Urbana-Champaign. He thanks Steven Rudolph and the U.S. Bureau of the Census for their work in creating the data set, Todd Elder and Wenxin Mao for help in data analysis, and Peter Cappelli, Fritz Drasgow, Kevin Hallock, Larry Hunter, Craig Olson, and Frits Pil for helpful comments on earlier drafts of this paper.

A public use version of this data set is available from the Census Bureau. unexplored topic of non-linearities in the relationships between innovative HR practices and organizational performance.

\section{Non-Linear Relationships with Performance in SHRM Research}

Provided that they are substantively meaningful, non-linearities in the relationships between innovative HR practices and organizational performance could be important to both academics and practitioners. For academics, estimates of meaningfully large non-linearities create more precise specifications of these relationships, which can inform inferences about how such relationships work. For practitioners, more precise estimates of SHRM relationships can prevent missteps in applying HR practices to achieving organizational goals.

Although a few scholars have pointed out the possibility of meaningfully non-linear relationships in reviews of the SHRM literature (for example, Becker and Gerhart 1996), with two exceptions, no empirical studies of HR systems and performance have explicitly examined them. The first exception is

Industrial and Labor Relations Review, Vol. 60, No. 4 (July 2007). (c) by Cornell University.

$0019-7939 / 00 / 6004 \$ 01.00$ 
Huselid and Becker's (1995) unpublished multi-industry study of the relationship between the degree of adoption of a system of HR practices and organizational performance. In the middle range of a generally positive relationship between $H R$ system adoption and organizational performance, Huselid and Becker found a plateau where the slope of this relationship was mostly flat. The second exception is Hitt, Bierman, Katsuhiko, and Kochhar's (2001) study of human capital in professional service firms. While the main relationship between human capital and performance was negative in this study, a quadratic term for human capital had a positive and statistically significant coefficient, suggesting an upward inflection in the estimated relationship.

\section{Theoretical Mechanisms}

Despite the paucity of attention to this issue in SHRM thus far, there are at least two theoretical reasons to believe that meaningfully large non-linearities could exist in the HRM $\rightarrow$ organizational performance relationship: scale effects of implementation and decreasing marginal utility. First, an HR practice may be able to generate greater positive effects on organizational performance from wide-scale implementation than would be available to organizations that have implemented the practice to a more limited degree. For example, if the percentage of the work force covered by job rotation in a given organization exceeds that in other organizations of equal size, the impact of job rotation on organizational performance may be higher in that organization because the fixed administrative expenses associated with job rotation are spread over more employees. ${ }^{1}$ Some HR practices may also be more effective in those organizations where the practices themselves are implemented intensely than in organizations where their implementation is more limited. For example, Schmidt and Hunter

\footnotetext{
${ }^{1}$ Note that this does not preclude the total costs of implementation from being higher in organizations where job rotation encompasses more workers, as the variable costs of job rotation are determined per worker covered by this practice.
}

(1998) demonstrated that employers may achieve higher selection validity if cognitive ability tests are coupled with certain other selection screening practices, such as work samples or structured interviews.

However, a non-linear relationship between the extent of implementation and performance exists only if increases in HR practice implementation are associated with exponential-not merely additively higherincreases in organizational performance. These scale effects of greater implementation will cause the slope of the relationship between an HR practice and organizational performance to be more positive for organizations at moderate to higher levels of $\mathrm{HR}$ practice implementation than for organizations at low implementation levels. In other words, an upward inflection in a positive relationship between the HR practice and organizational performance across organizations will be the result.

\section{HR Practices in This Study}

To lend precision to the hypotheses that follow, let us consider the above logic with respect to six specific $H R$ practices that are available in the data discussed below: self-managed teams, job rotation, quality meetings, intensive selection, average pay, and formal training expense. Each of these HR practices has figured prominently in theoretical discussions of "lean production" in the manufacturing sector and has been employed in published SHRM research using this concept. Thus, these HR practices should be applicable to the establishments in this paper's data set, which is restricted to manufacturing.

Self-managed teams (Arthur 1994; Guthrie 2001; Huselid 1995; MacDuffie 1995) are designed to further production goals by enhancing flexibility, capturing employees' knowledge, and raising their discretionary effort. Relatedly,job rotation is also intended to increase flexibility in production processes by maintaining employee interest and providing on-the-job cross-training (Ichniowski et al. 1997; MacDuffie 1995). Offline quality meetings capture valuable employee knowledge about improving production processes 
(Arthur 1994; Guthrie 2001; Huselid 1995; MacDuffie 1995). Each of these three variables (self-managed teams, job rotation, and offline quality meetings) is measured by the percentage of establishment workers who are covered by the respective practice.

Intensive selection is often recommended as a complement to HR practices that demand greater levels of skill, involvement, coordination, and adaptation from employees, such as those used in conjunction with lean production (Delaney and Huselid 1996; Huselid 1995; Ichniowski et al. 1997; MacDuffie 1995; Youndt et al. 1996). Because of these requirements, ill-fitted employees can do more damage to productivity in these systems than in traditional, Tayloristic production systems. The selection intensity variable in these data is the sum of five-point Likert scale responses concerning the importance of different recruiting sources (such as employee referrals and college recruiting) and selection criteria (such as attitude, education level, and industry-based credentials) in acquiring new establishment employees. There are nine different recruiting variables and ten different selection variables in these data. While practitioners often distinguish recruiting from selection, the items within these two categories comprise a consistent overall scale with a Cronbach alpha of 0.83 .

Compensation issues have also played a prominent role in lean manufacturing discussions (Wright et al. 1999; Youndt et al. 1996). The usual argument is that such production systems demand more skill, effort, attention, and the like from workers and that compensation has to be higher in order to attract and retain such workers as well as to motivate them sufficiently. The average pay variable is a weighted average of annual wages across five broad establishment job classes: managers, front line supervisors, technical staff, support staff, and production workers. The high Cronbach alpha $(0.85)$ for these items implies that an overall approach to compensation helps to set establishment wages within each job class, justifying the aggregation. I subtracted establishments' weighted average wage from their relevant industry-weighted average wage to account for industry wage effects.
Finally, lean manufacturing work systems usually require ongoing investments in worker training in order to maximize worker effectiveness in using other HR practices like those discussed above (Wright et al. 1999; Youndt etal. 1996). In these data, the variable measuring formal training expense has most establishments clustered in the low side of its range, which runs from $\$ 0$ to $\$ 1$ million. Thus, I use the natural logarithm of formal training expense in the analyses that follow. (To reduce the incidence of missing data for this variable, I added a constant of 1 before taking the logarithm.)

As a group, these variables reflect the kinds of HR practices that have been used in previous SHRM research in manufacturing settings, which has emphasized concepts such as participatory management (as in teams and quality meetings), flexible work organization (job rotation, for example), intensive selection and recruiting, compensation, and investments in training, as I do here (Dyer and Reeves 1995). Unfortunately, three types of $H R$ practices that have received attention in previous SHRM literature-job security, rewards and recognition (such as incentive compensation), and employee relations (for example, opinion surveys) - are not available for study. ${ }^{2}$ Moreover, while the six HR practice variables that I use here draw from different areas of concern that have defined previous research on high commitment work systems and lean manufacturing, they do not comprehensively encompass the HR practices included by various authors in their definitions of either concept. Of course, no other published SHRM research is immune to the same criticism, since there is no consensus operational definition of either high performance work systems or lean production, as observers have noted for some time (for example, Dyer and Reeves 1995). Furthermore, acquiring detailed data on organiza-

\footnotetext{
${ }^{2} A$ variable measuring one form of incentive compensation, a dummy indicating whether an establishment offered any of its workers stock options or profit-sharing, exists in the data set, but because this variable is not continuous, it is not amenable to the nonlinear analysis in this paper. No other variables from the three categories just mentioned exist in the data set.
} 
tions' HR practices from large samples is quite difficult, let alone obtaining data on a comprehensive set of the HR practices that appear in the SHRM literature.

The dependent variable in the analysis below is the natural logarithm of value added: an establishment's total sales for $1996 \mathrm{mi}$ nus production costs, including labor costs (corporate overhead is not included in the cost figure). The value added dependent variable gives a better picture of establishment efficiency than total sales with controls for establishment size, as production costs can vary substantially across establishments of comparable size. ${ }^{3}$ Thus, this dependent variable is well fitted to an examination of this paper's hypotheses, which concern the interplay of organizational costs and benefits from using innovative HR practices.

\section{Hypotheses}

The general argument given above for scale effects of HR practice implementation can now be examined with respect to these specific variables. One way in which scale effects of implementation may occur is if the fixed portions of an HR practice's administra-

\footnotetext{
${ }^{3}$ Indeed, as Cappelli and Neumark (2001) have demonstrated in analyses combining data similar to those that I use in this paper with other data sets, corresponding increases in labor costs can negate the value of increases in output due to innovative HR practices, resulting in negligible net gains for employers. For data measured at the establishment level, value added may be the most appropriate way to evaluate the financial impact of HRM, as it is a financial measure that is not confounded with other value-creating activities that could occur in other parts of the firm outside the establishment in question, as stock price and similar aggregated or capital market-based measures would be. Moreover, a financial outcome that is pertinent to the establishment level of analysis is necessary to test the mechanisms described in the paper's hypotheses, which are about costs of implementation versus benefits on one hand $(\mathrm{H} 1)$ and about declining benefits versus costs on the other hand (H2). Note that the log of value added has a somewhat truncated distribution, however, since negative values become missing when value added is logged, resulting in a $13.6 \%$ reduction of the available cases in the sample. Unfortunately, outcomes such as quantity and quality of output are not available in the data, though their effects on the firm's financial outcomes should be subsumed by the value added variable.
}

tive expenses are spread over larger proportions of an organizational work force such that the positive marginal impact of greater HR practice implementation on value added outpaces marginal increases in administrative costs. Since in these data self-managed teams, quality meetings, and job rotation are measured by the percentage of establishment workers covered by the HR practice in question, these three HR practice variables are suitable for detecting scale effects of implementation on value added through this mechanism. On the other hand, selection intensity and formal training expense are measured by the intensity with which establishments implement these practices. Thus, these two variables are suitable for detecting scale effects resulting from complementarities among different approaches to these two HR practices. Finally, the average pay variable is not suitable for assessing either type of scale effect of implementation on value added and serves as a comparison to the other HR practice variables.

Hypothesis 1. Across a sample of manufacturing establishments, each of five human resource practices-self-managed teams, job rotation, quality meetings, intensive selection, and formal training expense-will have a relationship with establishment value added that describes an increasingly positive slope as the level of implementation of the practice rises from zero.

For the second hypothesis, note that a simple linear model of the relationship between HR practices and organizational performance posits that a one-unit increment in an HR practice variable will consistently be linked to the same magnitude difference in the value of the dependent variable. Yet a standard assumption in modeling organizational performance is that the marginal utility of investments in organizational assets declines after some point (Pritchard and Roth 1991). Beyond this point of decreasing marginal returns, the slope of a positive relationship flattens and eventually may become negative as the incremental returns generated by further investments become increasingly less capable of recouping their costs. The empirical question, then, is not whether such points of decreasing returns occur but whether they have been observed 
in a particular data set. Yet, as noted above, almost no tests for such effects appear in the published SHRM literature.

In SHRM, decreasing marginal returns could result from non-random selection of workers into productivity-enhancing $\mathrm{HR}$ practices such as self-managed teams. If the workers who are most likely to show improvement from teams are selected into teams first, the incremental gains in productivity from increases in already high levels of team implementation in a work force are likely to be smaller than those generated by employees who were organized into teams at an earlier stage. Moreover, implementation and support costs may also dictate non-random selection into teams, with workers who are cheaper to organize into teams being subjected to this work practice first. Both mechanisms may lead to decreasing marginal returns. Again, since in these data self-managed teams, quality meetings, and job rotation are measured by the percentage of establishment workers covered by the HR practice in question, these three variables are suitable for detecting decreasing returns resulting from non-random selection of workers into these HR practices.

Another way in which decreasing returns could be observed across establishments is if employers tend to first use the most effective types of $\mathrm{HR}$ activities within an area of HR practice. If it is also true that the marginal costs of each incremental HR activity within an area of HR practice decline less quickly than the marginal benefits, decreasing marginal returns from greater implementation could result, in contrast to the above discussion leading to Hypothesis 1. For example, investments in training may exhibit decreasing returns if the kinds of training that have the biggest impact on organizational performance tend to be chosen first by decision-makers across a sample of establishments at the same time that the incremental costs of ratcheting up training activities remain relatively constant.

Although this logic is more amenable to testing with longitudinal data than with the cross-sectional data that I employ in this paper, I can make reasonable inferences by restricting the sample to manufacturing, where the quality of the control variables makes comparisons across establishments similar to comparisons within the same establishments at different levels of HR practice implementation over time because these controls capture a large part of the organizational heterogeneity (aside from the HR practice variables) that might affect value added.

Again, because of its construction, the average pay variable is not suitable for assessing either type of scale effect of implementation on value added and serves as a comparison to the other HR practice variables.

Hypothesis 2. Across a sample of manufacturing establishments, each of five human resource practices-self-managed teams, job rotation, quality meetings, intensive selection, and formal training expense-will have a relationship with establishment value added that exhibits decreasing returns at high levels of implementation.

These two hypotheses are complementary. Hypothesis 1 describes effects that should be most pronounced at limited levels of HR practice usage. By the logic of Hypothesis 2, however, a point exists at higher levels of HR practice implementation beyond which greater implementation will yield decreasing returns. If both scale effects and decreasing marginal returns occur across organizations within the same data set, the estimated relationship between an HR practice and value added will have two inflection points and could resemble the curve depicted in Figure 1.

\section{Data Set}

The data come from a national probability sample of private sector U.S. for-profit establishments (such as manufacturing plants and retail stores) with over twenty employees, a sampling frame representing approximately $85 \%$ of all establishments in the United States. Corporate headquarters were omitted from the sample. The survey was conducted in 1997 via telephone interviews by employees of the U.S. Bureau of the Census with at least one Census Bureau contact person at each establishment, each of whom was asked to report on establishment conditions during 1996. In the manufacturing sector, the 
Figure 1. Curve Consistent with both the Scale Effects of Implementation Hypothesis and the Decreasing Marginal Returns Hypothesis.

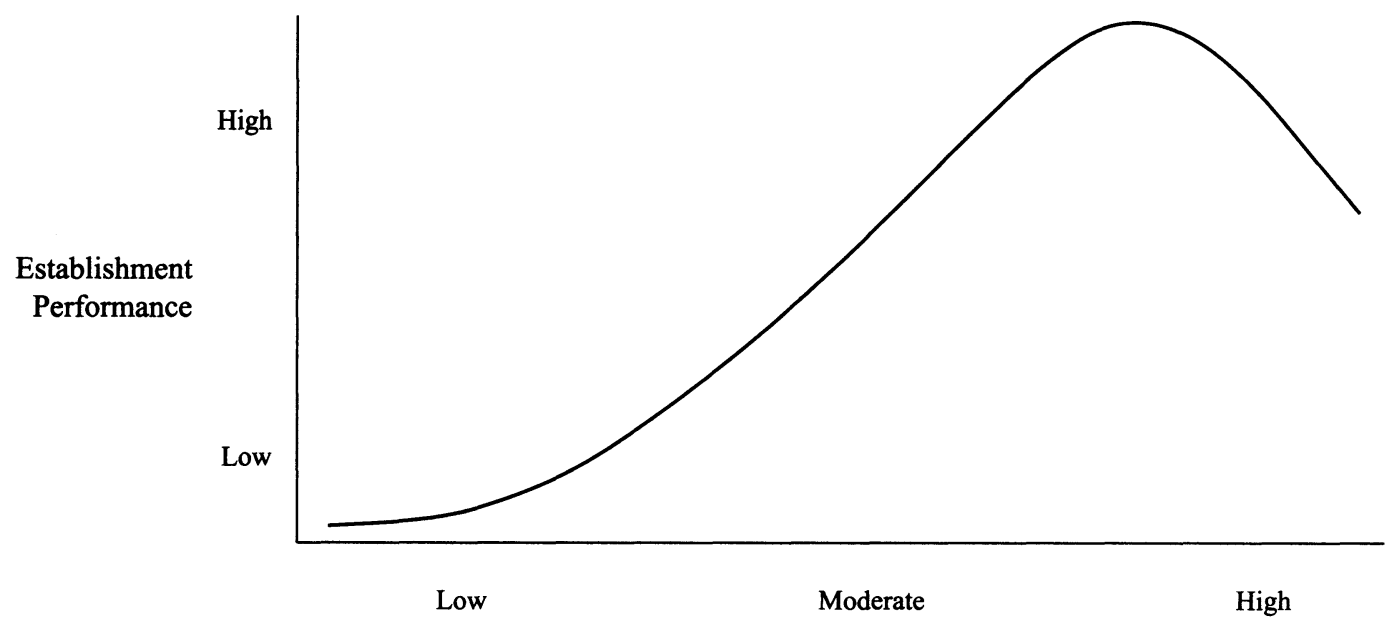

Degree of HR Practice Implementation within the Establishment

primary respondent was the plant manager. ${ }^{4}$ With some restrictions, these data are publicly available from the Census Bureau for further study of workplace issues by other scholars (Cappelli 2001). Usable data were received from a total of 3,081 establishments out of approximately 4,000 in the sampling frame, for a response rate of $77 \%$, which is substantially higher than in similar surveys. Based on its primary line of business, each establishment was assigned by the Census

\footnotetext{
${ }^{4}$ The fact that a single survey was used to gather the data can create concerns about spurious correlations between the variables in the analysis (Gerhart et al. 2000). This problem is mitigated by the fact that the ongoing informal reporting relationship between the survey respondents and the Census Bureau gave respondents a stronger incentive to provide accurate information than they would likely have had in a single-iteration survey conducted by researchers they did not know. Additionally, the survey is conducted at the establishment level, where, as Gerhart et al. observed, "smaller numbers of employees and presumably greater homogeneity of HR practices might be expected to yield higher reliabilities" (2000:829). Moreover, the dependent variable is anchored in factual reports that are readily available to respondents, and the survey was designed so that other respondents could provide those data if the main respondent was unsure about them.
}

to one of 21 different industries, organized roughly by two-digit SIC code, as shown in Table 1.

The analysis in this paper uses data from manufacturing establishments (industries 1-10 in Table 1). These establishments are $59 \%$ of the total sample. I omitted 615 manufacturing establishments due to missing data for the dependent variable, reducing the sample for this paper from 1,827 cases to 1,212 cases. $^{5}$ During part of the analysis

${ }^{5}$ There are also data missing for many of the other variables in the analysis. Although only $8 \%$ of the data are missing in the overall sample, because these missing data are scattered broadly across cases and variables, simple casewise deletion of missing data for all variables (in addition to the dependent variable) reduces the initial usable sample from 1,827 to 306 cases, dramatically reducing statistical power. Six variables have particularly large amounts of missing data: capital intensity, formal training expense, percent employment increase, and three of the pay variables (for managers, front line supervisors, and technical staff) that are aggregated into the average pay variable. Casewise deletion of missing data from these six variables alone reduces the usable sample to 395 cases.

I was able to mitigate the problem of missing data by using expectation-maximization (EM) imputation of missing values. EM employs maximum likelihood to converge iteratively on estimates of the missing values. 
Table 1. Distribution of 1997 NES Sample across Industries.

\begin{tabular}{|c|c|c|c|c|}
\hline $\begin{array}{l}\text { Industry } \\
\text { No. }\end{array}$ & $\begin{array}{l}\text { Industry Label and } \\
\text { 2-Digit SIC Code }\end{array}$ & $N$ & $\begin{array}{c}\% \text { of } \\
\text { Total Sample }\end{array}$ & $\begin{array}{c}\text { Cumulative } \\
\% \text { of Total } \\
\text { Sample }\end{array}$ \\
\hline 1 & Food (20) and Tobacco (21) & 197 & 6.4 & 6.4 \\
\hline 2 & Textiles (22) and Apparel (23) & 140 & 4.5 & 10.9 \\
\hline 3 & Lumber (24) and Paper (26) & 195 & 6.3 & 17.3 \\
\hline 4 & Printing and Publishing (27) & 172 & 5.6 & 22.8 \\
\hline 5 & Chemicals (28) and Petroleum (29) & 166 & 5.4 & 28.2 \\
\hline 6 & Primary Metals (33) & 200 & 6.5 & 34.7 \\
\hline 7 & Fabricated Metals (34) & 180 & 5.8 & 40.6 \\
\hline 8 & Machinery and Inst. $(35,36,38)$ & 200 & 6.5 & 47.1 \\
\hline 9 & Transportation Equipment (37) & 166 & 5.4 & 52.5 \\
\hline 10 & Other and Miscellaneous Manufacturing $(25,30,31,32)$ & 211 & 6.8 & 59.3 \\
\hline 11 & Construction (15-17) & 173 & 5.6 & 64.9 \\
\hline 12 & Transportation Services $(42,45)$ & 106 & 3.4 & 68.4 \\
\hline 13 & Communication (48) & 52 & 1.7 & 70.0 \\
\hline 14 & Utilities (49) & 112 & 3.6 & 73.7 \\
\hline 15 & Wholesale Trade $(50,51)$ & 137 & 4.4 & 78.1 \\
\hline 16 & Retail Trade $(52-59)$ & 116 & 3.8 & 81.9 \\
\hline 17 & Finance $(60-62)$ & 80 & 2.6 & 84.5 \\
\hline 18 & Insurance $(63,64)$ & 97 & 3.1 & 87.6 \\
\hline 19 & Hotels $(70)$ & 114 & 3.7 & 91.3 \\
\hline 20 & Business Services (73) & 121 & 3.9 & 95.3 \\
\hline 21 & Health Services $(80)$ & 146 & 4.7 & 100.0 \\
\hline
\end{tabular}

below, I split this 1,212-case sample into heavy manufacturing (647 cases) and light manufacturing (565 cases) subsamples. The manufacturing setting has a number of precedents in the published SHRM research, where significant straight-line relationships between $\mathrm{HR}$ practices and performance have been found in industries such as automobile assembly (MacDuffie 1995), steel production (Ichniowski et al. 1997; Arthur 1994), petro-chemicals (Wright et al. 1999), apparel (Dunlop and Weil 1996), general manufacturing (Lee and Miller 1999; Lam and White 1998), and heavy manufacturing (Dean and Snell 1996; Youndt et al. 1996).

\section{Variables}

The means, standard deviations, and definitions for the HR practice variables, control

Analyses using EM estimates of missing data have been demonstrated to be generally more consistent and efficient than those using regression imputation, mean substitution, casewise deletion, or pairwise deletion. This is especially true as the amount of missing data and the sample size increase (Arbuckle 1994). For ordinal variables, I rounded the values imputed by EM to the nearest integer (Schafer 1997). I do not use imputed values for the dependent variable. variables, and dependent variable that I use in the analysis are presented in Table 2. As the HR practice and dependent variables were explained above, I will not repeat that discussion here.

HR index. It has been common in previous SHRM research to aggregate $H R$ practice variables into indices to estimate the effects of HR systems (Delery 1998). I constructed such an index by summing standardized versions of the six HR practice variables and taking the mean (Batt 2002; MacDuffie 1995). Unfortunately, the Cronbach alpha for this index was quite low for a scale (0.44). However, as Batt (2002) and others have argued, additive indices are useful in SHRM because they can reflect substitution effects between HR practices that are theoretically related (for example, HR practices, like those here, that are designed to support the same broad production strategy, such as lean production) yet are not multiple indicators of a single, unobserved construct. ${ }^{6}$ Consequently, sta-

\footnotetext{
${ }^{6}$ Delery, quoting DeVellis (1991), has described this contrast between scales and indices as the difference between measuring a latent construct through related
} 
Table 2. Data Set Variable Descriptions and Descriptive Statistics.

Variable Mea

\section{HR Practice Variables}

Self-managed teams: Percentage of non-managerial and non-supervisory workers currently involved in self-managed teams.

17.03

Quality meetings: Percentage of non-managerial and non-supervisory workers currently involved in quality improvement meetings.

Job rotation: Percentage of non-managerial and non-supervisory workers currently involved in job rotation.

Selection intensity: Number of different recruiting sources (0-9) and selection criteria used $(0-10)$, weighted by a Likert response about the importance attached to each criterion (1-5 pts.). Cronbach alpha $=0.83$.

Average pay: A weighted average of annual wages across five broad job classes minus the relevant industry mean of this variable. Cronbach alpha $=0.85$.

Log of formal training expense: Natural log of the amount spent last year on formal training.

Additive index of six standardized HR practice variables. Cronbach alpha $=0.44$.

\section{Control Variables}

Log of capital intensity: Natural log of the total book value of the establishment's plant, equipment, and other capital stock.

Log of management levels: Natural log of the number of levels of management between first line supervisors and the establishment's top manager.

Log of percent managers: Natural log of managers as a percentage of the establishment's work force.

Labor intensity: Percent of production costs comprised by labor costs.

Unionization: Percentage of non-managerial and non-supervisory workers represented by a labor union.

Log of employment increase: Natural log of the percentage increase in the establishment's number of employees over the past 3 years.

Multi-establishment: Dummy indicating the establishment is part of a multiestablishment firm.

Size 1-49: Dummy variable indicating the establishment has 1-49 workers.

Size 50-99: Dummy variable indicating the establishment has 50-99 workers.

Size 100-249: Dummy variable indicating the establishment has 100-249 workers.

Size 250-999: Dummy variable indicating the establishment has 250-999 workers. (Omitted category is establishments with $1,000+$ workers.)

$\begin{array}{ll}2.50 & 0.73 \\ 0.70 & 0.46 \\ 0.12 & 0.32 \\ 0.15 & 0.36 \\ 0.18 & 0.39 \\ 0.37 & 0.48\end{array}$

\section{Dependent Variable}

Log of value added: Natural log of total establishment sales, receipts, or shipments minus costs for input labor and materials for 1996.

$\mathrm{N}=1,212$.

tistics such as Cronbach alpha that appraise the suitability of a scale are not appropriate in evaluating the usefulness of such indices (Delery 1998). (For a case in point, consider

variables that are "caused by an underlying construct" and using a set of variables to "determine the level of a construct," respectively (1998:297-300). that the selection intensity items are much more tightly related as multiple measures of a single construct, and this scale generates a Cronbach alpha of 0.83.) Moreover, the purpose of this index is to facilitate informational comparisons between the individual HR practices' effects and the effects of a typical aggregated HR measure rather than to validate a new HR management scale. 
Figure 2. Scatterplot of Unstandardized Regression Residuals and Log of Value Added.

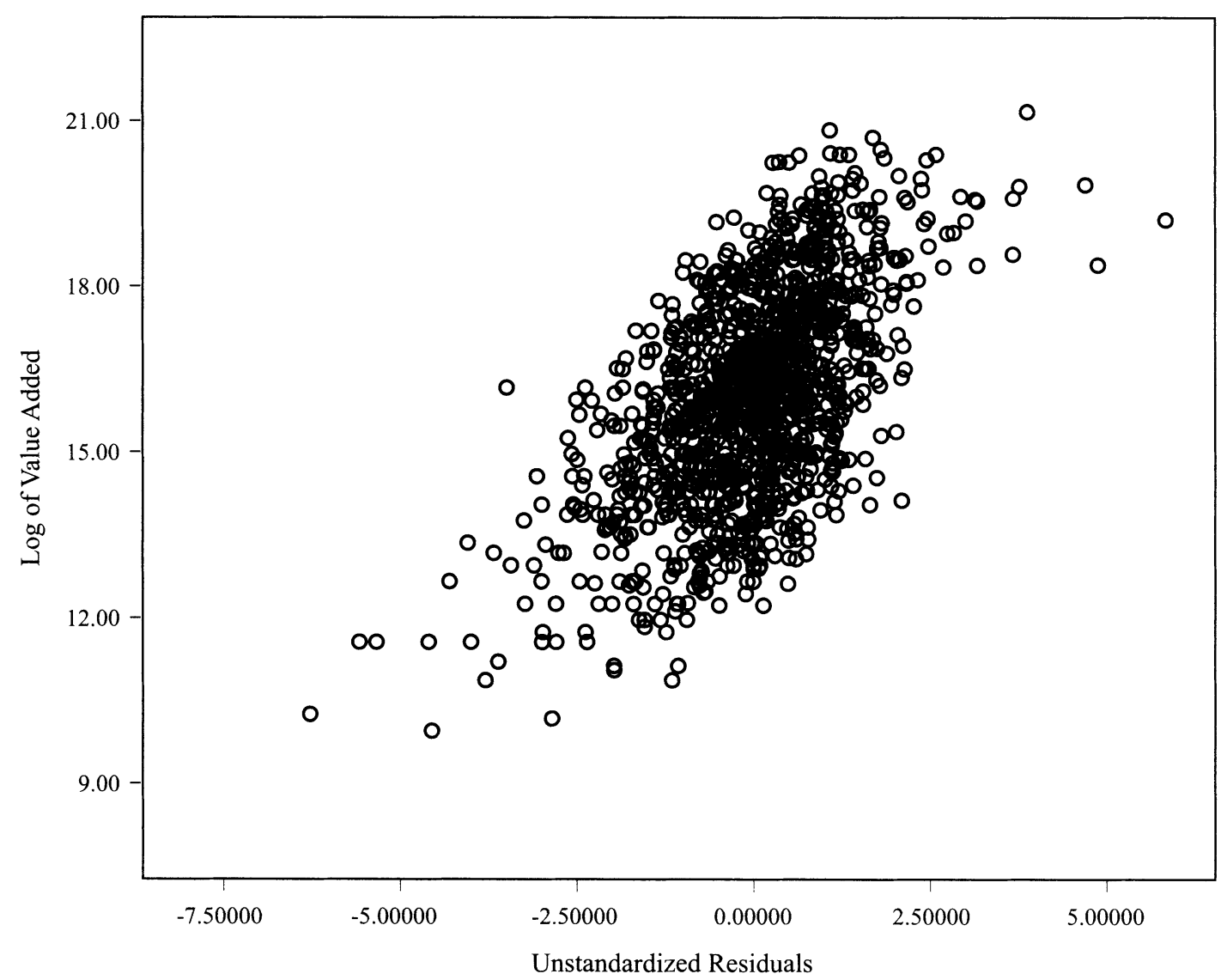

Control variables. The control variables capture key establishment characteristics that may plausibly be correlated both with establishment performance and with the HR practice variables. Many of these have been employed in previous SHRM research. These include capital intensity (Huselid, Jackson, and Schuler 1997; Koch and McGrath 1996), the number of management levels in the establishment, the percentage of employees who are managers (Delaney and Huselid 1996), labor intensity (Dunlop and Weil 1996; Huselid 1995), the percentage of non-supervisory and non-managerial workers who are unionized (Koch and McGrath 1996; Huselid 1995; Arthur 1994), and the percentage increase over the previous three years in the size of the establishment's work force. A number of these variables are expressed as natural logarithms to reduce non-normality in their distributions.

The controls also include dummy variables indicating whether the establishment is in a multi-establishment firm, the approximate number of employees in the establishment (Wright et al. 1999; Koch and McGrath 1996; Youndt, Snell, Dean, and Lepak 1996; Huselid 1995; Arthur 1994), and industry dummies at the two-digit SIC code level (Koch and McGrath 1996; Huselid 1995). Although a continuous variable giving establishment size in employees would be preferable to the establishment size dummies (see Table 2), 
the Census is unable to release those data in such a specific format. ${ }^{7}$

Correlations. Table 3 presents a correlation matrix for the variables used in the analyses below. A few relationships are worth noting here. A number of the HR practices as well as the HR index have statistically significant correlations with log of value added, as do some of the control variables, and these correlations generally run in the expected directions. The most striking relationship is the 0.69 correlation between log of capital intensity and $\log$ of value added. On the other hand, the relationship of labor intensity with $\log$ of value added, though statistically significant, is negative and much smaller in magnitude $(-0.15)$, and the correlation between capital intensity and labor intensity is smaller and negative, as well (-0.22). Thus, it appears that capital substitutes for labor in manufacturing, as could be expected, and generally this substitution is associated with higher establishment value added (the correlation between capital intensity and labor intensity would be much higher if these variables were measured in the same way). Additionally, four of the HR practice variables are not statistically significantly correlated with the labor intensity variable, and the magnitudes of the correlations with the other two HR practices, average pay and training expense, are low, suggesting that the HR practice variables are not simply proxies for the general importance of labor to a sample establishment.

${ }^{7}$ The Census has on-going informal reporting relationships with selected establishments across the spectrum of private sector establishments. The Census Bureau periodically uses these relationships to gather data on employment and business conditions in the United States. Part of the reason these relationships persist is that the Census Bureau is required to strictly guard the confidentiality of the respondent establishments. Consequently, the Census Bureau will not allow the data set to be used in ways that may enable someone outside the Census to determine or even narrow down the identity of specific respondent establishments. Among the devices that the Census employs for that purpose is substituting five establishment size category variables for the continuous size variable in the public release version of the data. This is unfortunate, but the unique combination of large sample size with detail about employment practices makes this data set extremely useful despite this drawback.

\section{Analysis}

Scatterplots. A simple descriptive approach to non-linearities is to generate a scatterplot of the dependent variable against the individual HR practice variables. These six scatterplots (not shown) reveal no obvious departures from linearity. A more precise procedure is to save the unstandardized residuals from an OLS regression employing the variables of interest in an analysis (in this case, the first model appearing in Table 4 below) and plot these residuals against the dependent variable. This approach accounts for the effects of the other independent variables in the model on the relationships between the HR practices and performance. If a linear model is sufficient to describe the relationships in the regression, the plot of the residuals should be normal and randomly distributed about zero. Instead, in these data, there is a broad upward slope in these points' distribution. The fact that this scatterplot implies structure suggests that non-linear techniques may help to explain some of the remaining variance in the relationship between the independent variables (including the HR practice variables) and the log of value added (see Figure 2).

Regressions. The models in Table 4 report a hierarchical set of OLS regressions employing polynomial terms to evaluate non-linearity, which is both a conservative and common approach to such questions. ${ }^{8}$

Although it does not appear in Table 4, a model employing just the control variables produced results that are quite consistent with the estimated coefficients reported for the

\footnotetext{
${ }^{8}$ To account for the patterns of missingness in the log of value added dependent variable, I initially employed a Heckman-style selection bias variable (Heckman 1979). This selection bias variable did not substantively alter the results reported below and was omitted from the final analysis. I also employ a weighting variable provided by the Census Bureau that corrects for small deviations in the sampling frame from a national probability sample. To account for the differences in measurement scales, I standardized all of the HR practice variables. Standardization also reduces the correlation between main effect terms and polynomials for the same HR practice variable, somewhat reducing the possibility of collinearity arising from adding the polynomials to the baseline models.
} 


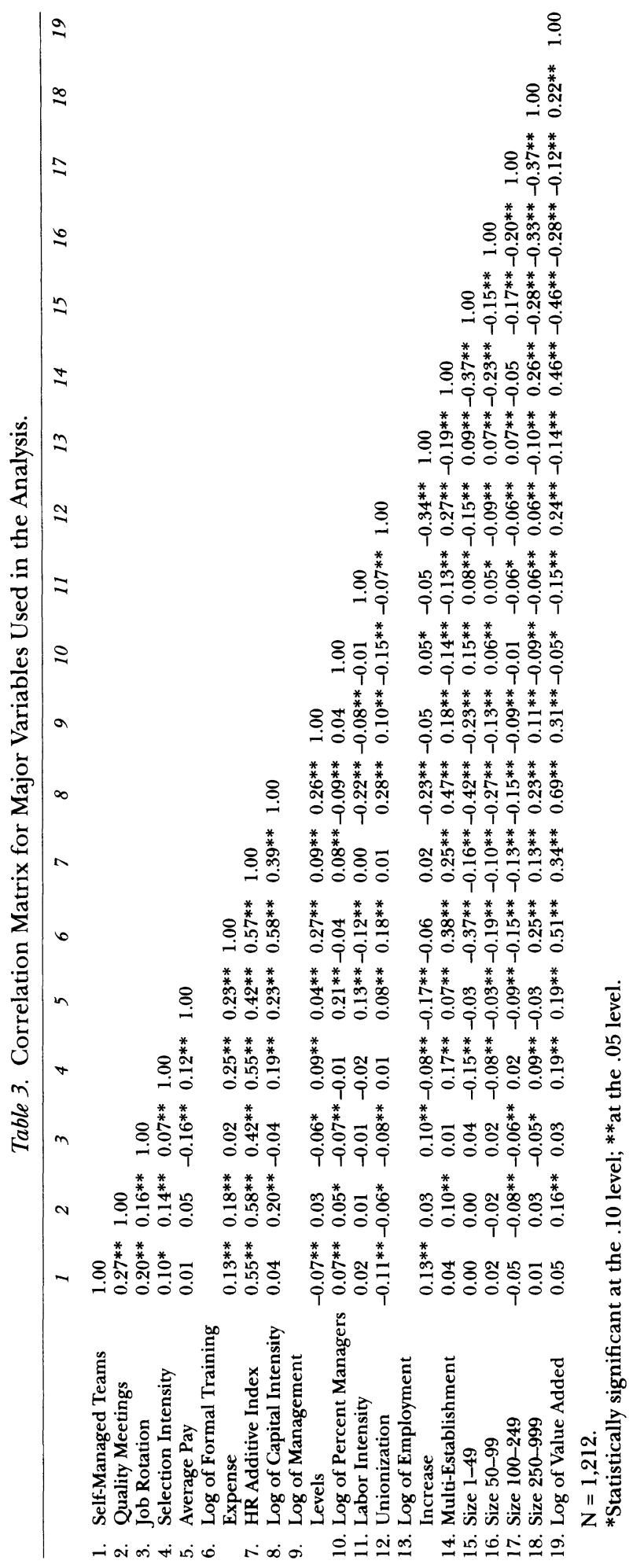


Table 4. Polynomial Regression Results for HR Practice Variables for the Full Manufacturing Sample. (Dependent Variable: Log of Value Added)

\begin{tabular}{|c|c|c|c|c|c|c|}
\hline Variable & $\begin{array}{l}\text { Model } 1 \\
\text { All Mfg. }\end{array}$ & $\begin{array}{l}\text { Model } 2 \\
\text { All Mfg. }\end{array}$ & $\begin{array}{l}\text { Model } 3 \\
\text { All Mfg. }\end{array}$ & $\begin{array}{l}\text { Model } 4 \\
\text { All Mfg. }\end{array}$ & $\begin{array}{l}\text { Model } 5 \\
\text { All Mfg. }\end{array}$ & $\begin{array}{l}\text { Model } 6 \\
\text { All Mfg. }\end{array}$ \\
\hline Constant & $13.74 * * *$ & $14.10 * * *$ & $14.57 * * *$ & $13.16 * * *$ & $13.17 * * *$ & $13.18^{* * *}$ \\
\hline Log of Capital Intensity & $0.23^{* * *}$ & $0.20 * * *$ & $0.19 * * *$ & $0.26^{* * *}$ & $0.26^{* * *}$ & $0.26^{* * *}$ \\
\hline Log of Management Levels & $0.17^{* * *}$ & $0.13^{* *}$ & $0.14 * *$ & $0.17 * * *$ & $0.17 * * *$ & $0.17^{* * *}$ \\
\hline Log of Percent Managers & $-0.09 *$ & $-0.12 * *$ & $-0.12 * *$ & -0.04 & -0.04 & -0.04 \\
\hline Labor Intensity & $-0.46^{* *}$ & $-0.54 * *$ & $-0.55^{* * *}$ & $-0.43 * *$ & $-0.43 * *$ & $-0.44 * *$ \\
\hline Unionization & 0.00 & 0.00 & 0.00 & 0.00 & 0.00 & 0.00 \\
\hline Log of Percent Employment Change & 0.03 & 0.02 & 0.01 & 0.02 & 0.02 & 0.02 \\
\hline Multi-Establishment & $0.29 * * *$ & $0.29 * * *$ & $0.31^{* * *}$ & $0.28 * * *$ & $0.28 * * *$ & $0.28^{* * *}$ \\
\hline Industry Dummies? & Yes & Yes & Yes & Yes & Yes & Yes \\
\hline Size $1-49$ & $-2.97 * * *$ & $-2.56 * * *$ & $-2.53 * * *$ & $-2.99 * * *$ & $-2.99 * * *$ & $-2.99 * * *$ \\
\hline Size 50-99 & $-2.19 * * *$ & $-1.85 * * *$ & $-1.79 * * *$ & $-2.18 * * *$ & $-2.18^{* * *}$ & $-2.18 * * *$ \\
\hline Size $100-249$ & $-1.72 * * *$ & $-1.41 * * *$ & $-1.35 * * *$ & $-1.73 * * *$ & $-1.73^{* * *}$ & $-1.73 * * *$ \\
\hline Size 250-999 & $-0.97 * * *$ & $-0.79 * *$ & $-0.75 * *$ & $-1.03 * * *$ & $-1.03^{* * *}$ & $-1.03 * * *$ \\
\hline Self-Managed Teams & $0.14 * * *$ & 0.10 & 0.11 & & & \\
\hline (Self-Managed Teams) $^{2}$ & & 0.01 & -0.09 & & & \\
\hline (Self-Managed Teams) $^{3}$ & & & 0.04 & & & \\
\hline Quality Meetings & -0.01 & -0.06 & $0.38^{* *}$ & & & \\
\hline (Quality Meetings) $^{2}$ & & $-0.19 * * *$ & $-0.35 * * *$ & & & \\
\hline (Quality Meetings) $^{3}$ & & & $-0.35^{* * *}$ & & & \\
\hline Job Rotation & $-0.08 * *$ & -0.10 & $-0.12 *$ & & & \\
\hline (Job Rotation) $^{2}$ & & 0.02 & $-0.22 *$ & & & \\
\hline (Job Rotation) $^{3}$ & & & $0.09 *$ & & & \\
\hline Selection Intensity & 0.05 & 0.02 & -0.04 & & & \\
\hline (Selection Intensity) $^{2}$ & & -0.02 & 0.00 & & & \\
\hline (Selection Intensity) $^{3}$ & & & $0.03 *$ & & & \\
\hline Average Pay & $0.23^{* * *}$ & $0.25^{* * *}$ & $0.27 * * *$ & & & \\
\hline (Average Pay) $^{2}$ & & $-0.04 *$ & -0.02 & & & \\
\hline (Average Pay) $^{3}$ & & & -0.03 & & & \\
\hline Log of Formal Training Expense & 0.04 & $0.51^{* * *}$ & $0.49 * * *$ & & & \\
\hline${\text { (Log of Formal Training Expense) }{ }^{2}}^{2}$ & & $0.19 * * *$ & $0.28 *$ & & & \\
\hline (Log of Formal Training Expense) $^{3}$ & & & 0.04 & & & \\
\hline HR Index & & & & $0.24 * * *$ & $0.24 * * *$ & $0.27 * *$ \\
\hline$(\text { HR Index })^{2}$ & & & & & -0.01 & 0.03 \\
\hline$(\text { HR Index })^{3}$ & & & & & & -0.05 \\
\hline Adjusted $\mathbf{R}^{2}$ & 0.58 & 0.59 & 0.59 & 0.57 & 0.57 & 0.57 \\
\hline F & $64.58 * * *$ & $54.93 * * *$ & $47.25 * * *$ & $76.05 * * *$ & $72.53 * * *$ & $69.34 * * *$ \\
\hline \multicolumn{7}{|l|}{ Change in Adjusted $\mathrm{R}^{2}$ vs. Controls } \\
\hline Model & 0.02 & 0.03 & 0.03 & 0.01 & 0.01 & 0.01 \\
\hline $\mathrm{N}$ & 1,212 & 1,212 & 1,212 & 1,212 & 1,212 & 1,212 \\
\hline
\end{tabular}

${ }^{*}$ Statistically significant at the .10 level; ${ }^{* *}$ at the .05 level; ${ }^{* * *}$ at the .01 level.

control variables in Table 4 (the one exception being log of percent managers, which has a statistically non-significant coefficient in the controls only regression). Moreover, the adjusted $\mathbf{R}^{2}$ of this model is fairly large (0.56). Consequently, I report the change in adjusted $R^{2}$ for each model in Table 4 versus the control model. These results for the controls strengthen the case for using a cross-section of establishments from manufacturing, where the control variables have good relevance, to test this paper's hypotheses.

The first model in Table 4 reports estimated linear effects for the HR practice variables. Here, self-managed teams and average pay are positively related to value added, job rotation is negatively related to value added, and the coefficients for quality meetings, 
Figure 3. Curves Fitted to the Estimated Relationships between Log of Value Added and Four HR Practice Variables.

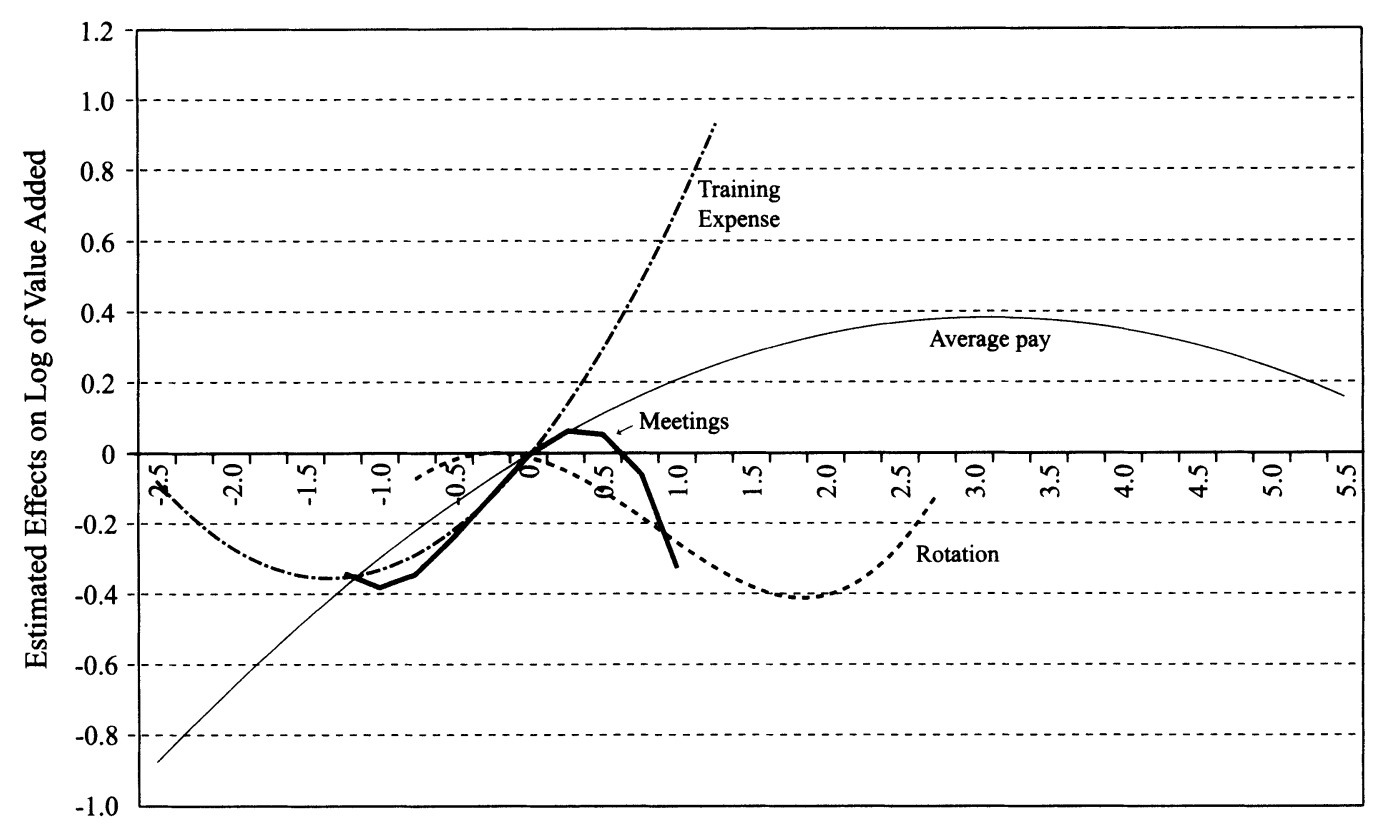

Standard Deviations of the Standardized HR Practice Variables

selection intensity, and average pay are not statistically significant.

Model 2 employs a group of quadratic terms for the six HR practice variables. Nonlinearity is determined by F-tests that evaluate the statistical significance of the change in $\mathbf{R}^{2}$ when polynomial terms are added to a model. As a group, the coefficients for the polynomials in Model 2 are significant ( $p$ $<0.001)$, an indication that the non-linear approach improves the fit of Model 1. Although there is the expected collinearity between main effects and the corresponding polynomial terms for each HR practice variable, diagnostic statistics indicate that little collinearity exists among the HR practice variables. Consequently, the coefficients from models identical to Model 1 except for the addition of a single HR practice's quadratic term (available upon request) change only slightly when all of these quadratic terms are included simultaneously, as shown in Model 2. In Model 2, the polynomials for quality meetings and average pay have statistically significant negative coefficients, while the polynomial for training expense has a statistically significant positive coefficient.

Model 3 reports the results when cubic polynomial terms for each of the HR practice variables are added to Model 2 and entered as a group. As before, these results are nearly identical to those from models in which a single cubic polynomial is added to Model 2 for each of the HR practices and also to models in which both the quadratic and cubic terms for only one HR practice are added to Model 1. Accordingly, to be both concise and conservative in reporting, I use the results from models employing all of the HR practice variables' quadratic and cubic polynomial terms concurrently, as they appear in Model 3. The coefficients for this group of variables in Model 3 are also significant as a group ( $p<0.001)$. Here, the cubic term for quality meetings has a statistically significant negative coefficient, while the cubic terms 
for job rotation and selection intensity have significant positive coefficients.

These results are more interpretable when plotted as in Figure 3, which depicts the best-fitting polynomial curve for quality meetings, average pay, quality meetings, and formal training expense, derived from the coefficients in Table 4.

To summarize these results, there is no statistically significant evidence of non-linearity for self-managed teams or selection intensity. For quality meetings and average pay, the quadratic terms' coefficients in Model 2 suggest a downward inflection consistent with Hypothesis 2, while in contrast, the quadratic for formal training expense indicates an upward inflection consistent with Hypothesis 1. In Model 3, the cubic term for quality meetings indicates an additional upward inflection consistent with Hypothesis 1. Finally, the Model 3 coefficients for job rotation indicate both an upward and downward inflection, but these coefficients map out a curve with inflections that are opposite those depicted in Figure 1: the downward inflection occurs first and the upward inflection occurs second.

Additive index results. Table 4 also reports regressions employing the additive index of the HR practices. When used in place of the six separate HR practices, this index has a positive and statistically significant relationship with value added, but none of its polynomial terms add significantly to adjusted $R^{2}$. Thus, the aggregation in this index may be masking statistically significant non-linearities between the individual $\mathrm{HR}$ practice variables and $\log$ of value added, perhaps because the interrelationships among the component HR practices are not especially strong and their separate relationships with value added differ. To examine this issue, I estimated models employing all 15 pairwise interactions between the six HR practice variables, added one at a time to Model 1 (available upon request). These results did not suggest an obvious pattern. Evaluated at the $\mathrm{p}<0.05$ level, the interaction between quality meetings and formal training expense is positive, while the three interactions between quality meetings and selection intensity, between selection in- tensity and average pay, and between training expense and average pay are negative.

Moreover, the bivariate correlations between the HR variables have fairly low magnitudes, and common aggregation techniques such as factor analysis do not yield good evidence that these practices should be combined. Thus, there is little evidence of substantial synergistic effects that would justify preferring an aggregated measure to using the individual HR practice variables as a group. This finding of an apparent lack of interactive effects parallels Cappelli and Neumark's (2001) results with the earlier (1993) version of this survey (only a portion of the respondent establishments in 1993 are in the 1997 data set). Of course, higher-order interactions among the HR practices might yield more statistically significant results, but such terms strain interpretability as their complexity grows. ${ }^{9}$

Results from subsamples. Another aspect of the analysis that may mask meaningful nuances in non-linear effects is the definition of the sample. The manufacturing sample comprises establishments from ten different two-digit SIC code industries ranging from food and tobacco (Industry 1 in Table 1) to lumber and paper (Industry 3 ) to chemicals and petroleum (Industry 5) to transporta-

\footnotetext{
${ }^{9}$ Besides the interrelationships rationale, it has also been argued that the additive index approach is particularly useful if important substitution effects between HR practices exist (Batt 2002; MacDuffie 1995), which would be indicated if some of the HR practices have very similar effects on the dependent variable, both in direction and magnitude, when estimated singly. If substitution effects are interactive, an aggregated measure such as the HR index would be preferable as a way to avoid misstating the impact of the individual HR practices. However, diagnostics indicate that collinearity between the HR practices is not an important issue. Consequently, the patterns of results I find for the independent variables are mostly robust with respect to the inclusion of the other HR practice variables in the same model, a finding that is consistent with the interaction results reported above, and the adjusted $\mathbf{R}^{2}$ for models employing the index is lower than for models using the HR practice variables separately. In other words, greater interpretive power lies in examining the HR practices as a group of separate variables per Models 1-3 in Table 4, and aggregation seems to mask the nuances of non-linear effects that differ across the HR practice variables.
} 
Table 5. Polynomial Regression Results for HR

Practice Variables across Two Manufacturing Subsamples.

(Dependent Variable: Log of Value Added)

\begin{tabular}{|c|c|c|c|c|c|c|}
\hline Variable & $\begin{array}{l}\text { Model } 1 \\
\text { Hvy } M f g .\end{array}$ & $\begin{array}{l}\text { Model } 1 \\
\text { Lt Mfg. }\end{array}$ & $\begin{array}{l}\text { Model } 2 \\
\text { Hvy Mfg. }\end{array}$ & $\begin{array}{l}\text { Model } 2 \\
\text { Lt Mfg. }\end{array}$ & $\begin{array}{l}\text { Model } 3 \\
\text { Hvy Mfg. }\end{array}$ & $\begin{array}{l}\text { Model } 3 \\
\text { Lt Mfg. }\end{array}$ \\
\hline Constant & $12.57 * * *$ & $15.69 * * *$ & $12.66^{* * *}$ & $16.58 * * *$ & $13.02 * * *$ & $16.79 * * *$ \\
\hline Log of Capital Intensity & $0.31 * * *$ & $0.15^{* * *}$ & $0.32 * * *$ & $0.10^{* * *}$ & $0.31^{* * *}$ & $0.09 *$ \\
\hline Log of Management Levels & 0.12 & $0.29 * * *$ & 0.02 & $0.27 * * *$ & 0.04 & $0.27 * * *$ \\
\hline Log of Percent Managers & $-0.17 * * *$ & 0.02 & $-0.20 * * *$ & -0.04 & $-0.20 * * *$ & -0.05 \\
\hline Labor Intensity & -0.37 & $-0.49 *$ & $-0.43^{*}$ & $-0.58 * *$ & $-0.50 *$ & $-0.61 * *$ \\
\hline Unionization & 0.00 & 0.00 & 0.00 & 0.00 & 0.00 & 0.00 \\
\hline Log of Percent Employment Increase & 0.01 & 0.03 & -0.02 & 0.04 & -0.04 & 0.04 \\
\hline Multi-Establishment & 0.09 & $0.49^{* * *}$ & 0.06 & $0.48^{* * *}$ & 0.08 & $0.49 * * *$ \\
\hline Industry Dummies? & Yes & Yes & Yes & Yes & Yes & Yes \\
\hline $\begin{array}{l}\text { Size } 1-49 \\
\text { Size } 50-99 \\
\text { Size } 100-249 \\
\text { Size } 250-999 \\
\text { Sample bias correction term }\end{array}$ & $\begin{array}{l}-2.48^{* * *} \\
-1.81 * * * \\
-1.52^{* * *} \\
-0.96^{* *}\end{array}$ & $\begin{array}{l}-3.53^{* * *} \\
-2.56^{* * *} \\
-1.81^{* * *} \\
-0.86^{*}\end{array}$ & $\begin{array}{l}-2.05^{* * *} \\
-1.42^{* * *} \\
-1.15^{* * *} \\
-0.70^{*}\end{array}$ & $\begin{array}{l}-3.26^{* * *} \\
-2.39^{* * *} \\
-1.63^{* * *} \\
-0.79^{*}\end{array}$ & $\begin{array}{l}-2.00^{* * *} \\
-1.37 * * * \\
-1.10^{* * *} \\
-0.68 *\end{array}$ & $\begin{array}{l}-3.19 * * * \\
-2.30^{* * *} \\
-1.52 * * \\
-0.71\end{array}$ \\
\hline $\begin{array}{l}\text { Self-Managed Teams } \\
\text { (Self-Managed Teams) }^{2} \\
\text { (Self-Managed Teams) }^{3}\end{array}$ & $0.18^{* * *}$ & $0.11 * *$ & $\begin{array}{l}0.27 * * \\
-0.06\end{array}$ & $\begin{array}{r}-0.03 \\
0.07\end{array}$ & $\begin{array}{l}0.30^{* *} \\
-0.36 \\
0.10\end{array}$ & $\begin{array}{r}-0.08 \\
0.30 \\
-0.08\end{array}$ \\
\hline $\begin{array}{l}\text { Quality Meetings } \\
\text { (Quality Meetings) }^{2} \\
\text { (Quality Meetings) }^{3}\end{array}$ & -0.03 & -0.01 & $\begin{array}{l}-0.11^{* *} \\
-0.37 * * *\end{array}$ & $\begin{array}{l}-0.04 \\
-0.04\end{array}$ & $\begin{array}{l}0.16 \\
-0.45^{* * *} \\
-0.20\end{array}$ & $\begin{array}{l}0.45^{* *} \\
-0.25 * \\
-0.39 * *\end{array}$ \\
\hline 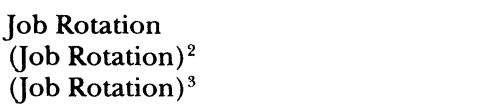 & $-0.10^{* *}$ & $-0.11 * *$ & $\begin{array}{l}-0.20^{* *} \\
0.06\end{array}$ & $\begin{array}{r}0.03 \\
-0.06\end{array}$ & $\begin{array}{l}-0.21 * * \\
-0.09 \\
0.06\end{array}$ & $\begin{aligned}-0.08 \\
-0.57 * * * \\
0.21 * * *\end{aligned}$ \\
\hline $\begin{array}{l}\text { Selection Intensity } \\
\text { (Selection Intensity) }^{2} \\
\text { (Selection Intensity) }^{3}\end{array}$ & 0.03 & 0.01 & $\begin{array}{l}-0.03 \\
-0.06^{*}\end{array}$ & $\begin{array}{l}0.00 \\
0.02\end{array}$ & $\begin{array}{l}-0.13^{*} \\
-0.02 \\
0.04^{*}\end{array}$ & $\begin{array}{l}0.02 \\
0.03 \\
0.00\end{array}$ \\
\hline $\begin{array}{l}\text { Average Pay } \\
\text { (Average Pay) }^{2} \\
\text { (Average Pay) }^{3}\end{array}$ & 0.12 & $0.31 * * *$ & $\begin{array}{l}0.11 \\
0.11\end{array}$ & $\begin{array}{r}0.57 * * * \\
-0.10^{* * *}\end{array}$ & $\begin{array}{r}0.13 \\
0.10 \\
-0.01\end{array}$ & $\begin{array}{l}0.53^{* * *} \\
-0.13^{* *} \\
0.01\end{array}$ \\
\hline $\begin{array}{l}\text { Log of Formal Training Expense } \\
\text { (Log of Formal Training Expense) }^{2} \\
\text { (Log of Formal Training Expense) }^{3}\end{array}$ & $0.23 * * *$ & $-0.26^{* * *}$ & $\begin{array}{l}0.56^{* * *} \\
0.14^{* *}\end{array}$ & $\begin{array}{l}0.18 \\
0.18^{* * *}\end{array}$ & $\begin{array}{l}0.62 * * * \\
0.10 \\
-0.02\end{array}$ & $\begin{array}{l}0.08 \\
0.42^{*} \\
0.10\end{array}$ \\
\hline $\begin{array}{l}\text { Adjusted } \mathbf{R}^{2} \\
\mathbf{F}\end{array}$ & $\begin{array}{l}0.59 \\
44.30^{* * *}\end{array}$ & $\begin{array}{l}0.63 \\
46.25^{* * *}\end{array}$ & $\begin{array}{l}0.60 \\
37.31^{* * *}\end{array}$ & $\begin{array}{l}0.64 \\
38.81^{* * *}\end{array}$ & $\begin{array}{l}0.60 \\
30.82 * * *\end{array}$ & $\begin{array}{l}0.65 \\
32.90^{* * *}\end{array}$ \\
\hline \multicolumn{7}{|l|}{ Change in Adjusted $\mathrm{R}^{2}$ vs. Controls } \\
\hline Model & $\begin{array}{r}0.04 \\
647\end{array}$ & $\begin{array}{c}0.03 \\
565\end{array}$ & $\begin{array}{r}0.05 \\
647\end{array}$ & $\begin{array}{r}0.04 \\
565\end{array}$ & $\begin{array}{r}0.05 \\
647\end{array}$ & $\begin{array}{r}0.05 \\
565\end{array}$ \\
\hline
\end{tabular}

Note: For heavy manufacturing, $\mathrm{N}=647$. For light manufacturing, $\mathrm{N}=565$.

*Statistically significant at the .10 level; **at the .05 level; ***at the .01 level.

tion equipment (Industry 9). This raises a concern that the non-linearities examined thus far could be artifacts of unobserved heterogeneity generated by including disparate manufacturing industries in the same analysis. I can partially address this issue by dividing the sample into two more homogeneous groupings, light manufacturing and heavy manufacturing, and comparing the results. Table 5 displays results for the same models that were reported in Table 4, but for the heavy manufacturing and light manufacturing subsamples separately. To aid comparisons, results for the same model from the two samples appear side by side, and I give the statistical significance of the differences between corresponding coefficients from paired models in the text of the 
paper when they reach conventional levels (that is, $\mathrm{p}<0.10$ ).

For Model 1 (the linear model), self-managed teams has a smaller coefficient in light manufacturing than in heavy manufacturing, but both coefficients run in the same direction. The full sample model's coefficient for self-managed teams in Table $4(0.14)$ falls roughly in the middle of these two point estimates. Similarly, job rotation's coefficients are statistically significant and run in the same direction across both samples. Also, quality meetings and selection intensity have small coefficients that are not statistically significant in either sample, just as was the case in the full manufacturing sample. In contrast, the statistically significant positive coefficient for average pay in the full sample $(0.23)$ appears to be driven by the larger positive coefficient in light manufacturing $(p<0.01$ for the difference in coefficients across the two subsamples). An even bigger difference occurs for formal training expense, which has statistically significant coefficients that are nearly the same magnitude but opposite in sign across the two subsamples $(\mathrm{p}<0.001$ for the contrast in coefficients). Perhaps it is not surprising, then, that formal training expense has a small (0.04) and statistically non-significant coefficient in the full sample model in Table 4. Thus, for two of the six HR practice variables, average pay and training expense, the estimates of their linear effects are statistically significantly different across the two manufacturing subsamples.

Model 2 and Model 3 in Table 5 address whether these differences appear in the polynomial estimates, as well. In Model 2, the results for self-managed teams and job rotation do not change from the full manufacturing sample: all quadratics have statistically non-significant coefficients. Formal training expense has a positive and statistically significant coefficient for its quadratic term in the full sample and in each manufacturing subsample, although the magnitudes vary somewhat across subsamples. On the other hand, selection intensity, which has statistically non-significant coefficients in the full sample and in light manufacturing, has a statistically significant negative coefficient $(-0.06)$ in heavy manufacturing. More dramatically, the variable quality meetings, which has a statistically significant negative coefficient $(-0.19)$ for its quadratic term in the full sample, has a statistically significant negative coefficient $(-0.37)$ in heavy manufacturing, but not in light manufacturing ( $p$ $<0.001$ for the contrast in coefficients). The coefficients for the average pay variable have opposite signs across the two subsamples, although the heavy manufacturing coefficient is not quite significant $(p<0.13)$, compared to a smaller but significant negative coefficient $(-0.04)$ for the average pay quadratic in the full sample. This contrast in coefficients across the two subsamples is significant $(p<0.001)$. Thus, the estimated quadratic coefficients for two of the six HR practice variables, quality meetings and average pay, differ significantly across the two manufacturing subsamples. ${ }^{10}$

For the cubic terms in Model 3, the signs of the coefficients for self-managed teams vary across the two subsamples, but, just as in the full sample model, these coefficients are not statistically significant. Training expense, also, does not have statistically significant cubic effects in either the subsamples or the full sample. Quality meetings has statistically significant cubic effects in the full sample and in the light manufacturing subsample, and these effects are consistent with those in heavy manufacturing, albeit the level of significance is lower in the latter subsample ( $p<0.001$ for the contrast in cubic terms' coefficients). Job rotation, too, has results that run in the same direction across both subsamples, but with lesser magnitudes and statistical significance in heavy manufacturing ( $\mathrm{p}<0.05$ for the contrast in cubic terms' coefficients). For selection intensity, there is some evidence of cubic structure in heavy manufacturing, but the difference across the subsamples is not statistically significant. For

\footnotetext{
${ }^{10}$ However, because collinearity with main effects terms makes point estimates of polynomial terms' coefficients somewhat unstable, these differences across the two subsamples are not definitive. The shapes of curves such as those depicted in Figure 3 are true to the estimated model because they take into account all of the coefficients related to an HR practice, both for main effects terms and for polynomial terms.
} 
Table 6. Polynomial Regression Results for the HR Index across Two Manufacturing Subsamples.

(Dependent Variable: Log of Value Added)

\begin{tabular}{|c|c|c|c|c|c|c|}
\hline Variable & $\begin{array}{c}\text { Model } 4 \\
\text { Hvy Mfg. }\end{array}$ & $\begin{array}{l}\text { Model } 4 \\
\text { Lt Mfg. }\end{array}$ & $\begin{array}{c}\text { Model } 5 \\
\text { Hvy Mfg. }\end{array}$ & $\begin{array}{l}\text { Model } 5 \\
\text { Lt Mfg. }\end{array}$ & $\begin{array}{c}\text { Model } 6 \\
\text { Hvy Mfg. }\end{array}$ & $\begin{array}{l}\text { Model } 6 \\
\text { Lt Mfg. }\end{array}$ \\
\hline Constant & $11.81 * * *$ & $15.61 * * *$ & $11.95^{* * *}$ & $15.47 * * *$ & $11.93^{* * *}$ & $15.47^{* * *}$ \\
\hline Log of Capital Intensity & $0.35^{* * *}$ & $0.15^{* * *}$ & $0.35^{* * *}$ & $0.15^{* * *}$ & $0.35^{* * *}$ & $0.15^{* * *}$ \\
\hline Log of Management Levels & $0.16^{*}$ & $0.20^{* *}$ & 0.14 & $0.20^{* *}$ & $0.15^{*}$ & $0.21 * *$ \\
\hline Log of Percent Managers & $-0.13^{* *}$ & 0.11 & $-0.13^{* *}$ & 0.11 & $-0.13^{* *}$ & 0.11 \\
\hline Labor Intensity & -0.36 & $-0.54^{*}$ & -0.33 & $-0.52 *$ & -0.32 & $-0.53 *$ \\
\hline Unionization & 0.00 & 0.00 & 0.00 & 0.00 & 0.00 & 0.00 \\
\hline \multicolumn{7}{|l|}{ Log of Percent Employment } \\
\hline Increase & 0.04 & -0.04 & 0.03 & -0.07 & 0.03 & -0.07 \\
\hline Multi-Establishment & 0.14 & $0.45^{* * *}$ & 0.13 & $0.46^{* * *}$ & 0.13 & $0.45^{* * *}$ \\
\hline Industry Dummies? & Yes & Yes & Yes & Yes & Yes & Yes \\
\hline Size $1-49$ & $-2.63 * * *$ & $-3.43 * * *$ & $-2.66 * * *$ & $-3.39 * * *$ & $-2.65^{* * *}$ & $-3.39 * * *$ \\
\hline Size 50-99 & $-1.86 * * *$ & $-2.47 * * *$ & $-1.90 * * *$ & $-2.43 * * *$ & $-1.89 * * *$ & $-2.42 * * *$ \\
\hline Size 100-249 & $-1.56^{* * *}$ & $-1.79 * * *$ & $-1.59 * * *$ & $-1.75^{* * *}$ & $-1.59 * * *$ & $-1.75^{* * *}$ \\
\hline Size 250-999 & $-1.02 * *$ & $-0.90 *$ & $-1.04 * * *$ & $-0.88^{*}$ & $-1.04 * * *$ & $-0.88^{*}$ \\
\hline HR Index & $0.42 * * *$ & -0.15 & $0.37 * * *$ & -0.09 & $0.29 *$ & -0.02 \\
\hline$(\text { HR Index })^{2}$ & & & -0.17 & $0.25^{* *}$ & -0.14 & $0.23 *$ \\
\hline$(\text { HR Index })^{3}$ & & & & & 0.11 & -0.08 \\
\hline Adjusted $\mathbf{R}^{2}$ & 0.56 & 0.60 & 0.56 & 0.60 & 0.56 & 0.60 \\
\hline$F^{J}$ & $53.01 * * *$ & $54.06 * * *$ & $50.13 * * *$ & $51.42 * * *$ & $47.32 * * *$ & $48.52 * * *$ \\
\hline \multicolumn{7}{|l|}{ Change in Adjusted $\mathrm{R}^{2}$ vs. Controls } \\
\hline Model & 0.01 & 0.00 & 0.01 & 0.00 & 0.01 & 0.00 \\
\hline $\mathbf{N}$ & 647 & 565 & 647 & 565 & 647 & 565 \\
\hline
\end{tabular}

Note: For heavy manufacturing, $\mathrm{N}=647$. For light manufacturing, $\mathrm{N}=565$.

${ }^{*}$ Statistically significant at the .10 level; ${ }^{* *}$ at the .05 level; ***at the .01 level.

average pay, the different signs for quadratic terms across the two samples carry over from Model 2 to Model 3, but in no cases are there statistically significant cubic term coefficients for this variable. Thus, the differences found across the two manufacturing subsamples for the cubic models in Table 5 are mostly differences in coefficient magnitude and significance, not in direction.

Table 6 gives the same comparisons for the HR index models. Here, the index's main effect coefficient has a larger magnitude in heavy manufacturing $(\mathrm{p}<0.001$ for the contrast in coefficients), while the quadratic coefficients change sign across the two subsamples $(p<0.001$ for the contrast in coefficients). The quadratic term in heavy manufacturing falls just short of conventional levels of significance $(p<0.14)$. The coefficients for the HR index's cubic terms are not statistically significant.

Overall, there is limited evidence of meaningful differences across the two subsamples. The results for self-managed teams do not change at all across the two samples, and the differences across the two subsamples for selection intensity and formal training expense are not statistically significant. For quality meetings and job rotation, there are variations in the magnitude and statistical significance of the coefficients across subsamples, but no changes in the signs or substantive meaning of the results. Average pay has the largest difference, with a larger positive main effect and a negative quadratic effect in the light manufacturing subsample. The HR index results also suggest that the two subsamples differ in non-linearity, as the estimated models map out opposite quadratic inflections. This implies that the differences for the index may be driven by the average pay variable. To investigate this possibility, I recomputed the HR index, dropping average pay, and reestimated the models in Table 6 using this new version of the index (models not shown). The results in Table 6 hold, with some slight increases rather than decreases in non-linearity differences across the two 
Table 7. Estimated Effects of the HR Practice Variables on Log of Value Added.

\begin{tabular}{|c|c|c|c|c|c|c|c|c|}
\hline $\begin{array}{l}\text { Standard } \\
\text { Deviations of } \\
\text { the HR } \\
\text { Practice } \\
\text { Variables }\end{array}$ & $\begin{array}{l}\text { Linear } \\
\text { Model: } \\
\text { Average } \\
\text { Pay }\end{array}$ & $\begin{array}{c}\text { Quadratic } \\
\text { Model: } \\
\text { Average } \\
\text { Pay }\end{array}$ & $\begin{array}{l}\text { Linear } \\
\text { Model: } \\
\text { Training } \\
\text { Expense }\end{array}$ & $\begin{array}{l}\text { Quadratic } \\
\text { Model: } \\
\text { Training } \\
\text { Expense }\end{array}$ & $\begin{array}{l}\text { Linear } \\
\text { Model: } \\
\text { Quality } \\
\text { Meetings }\end{array}$ & $\begin{array}{c}\text { Cubic } \\
\text { Model: } \\
\text { Quality } \\
\text { Meetings }\end{array}$ & $\begin{array}{l}\text { Linear } \\
\text { Model: } \\
\text { Job } \\
\text { Rotation }\end{array}$ & $\begin{array}{l}\text { Cubic } \\
\text { Model: } \\
\text { Job } \\
\text { Rotation }\end{array}$ \\
\hline $\begin{array}{c}-3.5 \mathrm{sd} \\
-3 \mathrm{sd}\end{array}$ & -0.69 & $\begin{array}{l}-1.11 \\
(-0.42)\end{array}$ & & & & & & \\
\hline$-2.5 \mathrm{sd}$ & -0.58 & $\begin{array}{c}-0.88 \\
(-0.30)\end{array}$ & -0.10 & $\begin{array}{l}-0.09 \\
(0.01)\end{array}$ & & & & \\
\hline$-2 s d$ & -0.46 & $\begin{array}{c}-0.66 \\
(-0.20)\end{array}$ & -0.08 & $\begin{array}{c}-0.26 \\
(-0.18)\end{array}$ & & & & \\
\hline$-1.5 \mathrm{sd}$ & -0.35 & $\begin{array}{c}-0.47 \\
(-0.12)\end{array}$ & -0.06 & $\begin{array}{c}-0.34 \\
(-0.28)\end{array}$ & 0.02 & $\begin{array}{c}-0.18 \\
(-0.20)\end{array}$ & & \\
\hline$-1 s d$ & -0.23 & $\begin{array}{l}-0.29 \\
(-0.06)\end{array}$ & -0.04 & $\begin{array}{c}-0.32 \\
(-0.28)\end{array}$ & 0.01 & $\begin{array}{c}-0.38 \\
(-0.39)\end{array}$ & & \\
\hline$-0.5 \mathrm{sd}$ & -0.12 & $\begin{array}{l}-0.14 \\
(-0.02)\end{array}$ & -0.02 & $\begin{array}{l}-0.21 \\
(-0.19)\end{array}$ & 0.01 & $\begin{array}{l}-0.23 \\
(-0.24)\end{array}$ & 0.04 & $\begin{array}{c}-0.01 \\
(-0.05)\end{array}$ \\
\hline 0 (Mean) & 0 & $\begin{array}{c}0 \\
(-)\end{array}$ & 0 & $\begin{array}{c}0 \\
(-)\end{array}$ & 0 & $\begin{array}{c}0 \\
(-)\end{array}$ & 0 & $\begin{array}{c}0 \\
(-)\end{array}$ \\
\hline $0.5 \mathrm{sd}$ & 0.12 & $\begin{array}{l}0.12 \\
(-)\end{array}$ & 0.02 & $\begin{array}{c}0.30 \\
(0.28)\end{array}$ & -0.01 & $\begin{array}{c}0.06 \\
(0.07)\end{array}$ & -0.04 & $\begin{array}{c}-0.10 \\
(-0.06)\end{array}$ \\
\hline $1 \mathrm{sd}$ & 0.23 & $\begin{array}{c}0.21 \\
(-0.02)\end{array}$ & 0.04 & $\begin{array}{c}0.70 \\
(0.66)\end{array}$ & -0.01 & $\begin{array}{c}-0.32 \\
(-0.31)\end{array}$ & -0.08 & $\begin{array}{c}-0.25 \\
(-0.17)\end{array}$ \\
\hline $1.5 \mathrm{sd}$ & 0.35 & $\begin{array}{c}0.29 \\
(-0.06)\end{array}$ & 0.06 & $\begin{array}{c}1.19 \\
(1.13)\end{array}$ & & & -0.12 & $\begin{array}{c}-0.37 \\
(-0.25)\end{array}$ \\
\hline $2 \mathrm{sd}$ & 0.46 & $\begin{array}{c}0.34 \\
(-0.12)\end{array}$ & & & & & -0.16 & $\begin{array}{l}-0.40 \\
(-0.24)\end{array}$ \\
\hline $2.5 \mathrm{sd}$ & 0.58 & $\begin{array}{c}0.38 \\
(-0.20)\end{array}$ & & & & & -0.20 & $\begin{array}{c}-0.27 \\
(-0.07)\end{array}$ \\
\hline $3 \mathrm{sd}$ & 0.69 & $\begin{array}{c}0.39 \\
(-0.30)\end{array}$ & & & & & & \\
\hline $3.5 \mathrm{sd}$ & 0.81 & $\begin{array}{c}0.39 \\
(-0.42)\end{array}$ & & & & & & \\
\hline $4 \mathrm{sd}$ & 0.92 & $\begin{array}{c}0.36 \\
(-0.56)\end{array}$ & & & & & & \\
\hline $4.5 \mathrm{sd}$ & 1.04 & $\begin{array}{c}0.32 \\
(-0.72)\end{array}$ & & & & & & \\
\hline $5 \mathrm{sd}$ & 1.15 & $\begin{array}{c}0.25 \\
(-0.90)\end{array}$ & & & & & & \\
\hline $5.5 \mathrm{sd}$ & 1.27 & $\begin{array}{c}0.17 \\
(-1.10)\end{array}$ & & & & & & \\
\hline
\end{tabular}

Notes: Numbers in parentheses are differences in the values for the polynomial model estimates versus the linear estimates for each HR practice variable, drawn from the results in Table 4. Results are given for the extant values for each variable, rounded to the nearest 0.5 standard deviation.

subsamples.

\section{Magnitudes of Results}

But do these non-linearities really matter in the bottom-line sense that suffuses SHRM research? One way of addressing this question is to examine how the estimated linear effects of the HR practice variables on the log of value added compare with an HR practice's most appropriate non-linear model. Table 7 gives these estimated effects 
from the models in Table 4 across the extant range of values for average pay, formal training expense, quality meetings, and job rotation, the four variables for which statistically significant results were found in the polynomial analyses.

Table 7 demonstrates how linear estimations misstate the effects of average pay, formal training expense, quality meetings, and job rotation on $\log$ of value added. In absolute terms, the divergences between the linear and polynomial models' estimates are as large as 1.13, which is over half of the log of value added variable's standard deviation (1.92), though most divergences are considerably smaller; the mean discrepancy across the linear-polynomial cell comparisons in Table 7 is 0.26 . Since value added is a logged dependent variable, the size of these discrepancies in dollars depends greatly on the point in its distribution at which a coefficient's effect is translated, which is given by the expression $\exp \left(\ln Y_{i}+B_{i} s d X_{i}\right)-\exp \left(\ln Y_{i}\right)$. For example, for an establishment at the mean level of $\log$ of value added, an impact of a -0.26 change in the estimated log of value added is a reduction of $\$ 2$ million in value added. For an establishment one standard deviation below the mean log of value added, the same discrepancy in estimated log of value added means a reduction of $\$ 298,000$ in value added. For an establishment one standard deviation above the mean log of value added, the same discrepancy in estimated log of value added indicates a reduction of nearly $\$ 14$ million value added.

While these numbers may at first blush seem excessively large, note that the distribution of the value added variable before it was logged ranged from $\$ 20,000$ to $\$ 1,476,000,000$, with a mean of $\$ 40$ million. Thus, these estimated effects are proportional to the size of the value added variable, and even seemingly small differences in estimates between linear models and models accounting for non-linearity can be substantively meaningful. The fact that many of the non-linear estimates' differences with their respective linear models in Table 7 are reductions in estimated $\log$ of value added suggests that the linear models may often markedly overstate the relationship of the HR practice variables with $\log$ of value added. Of course, these estimated effect sizes must be taken with caution, as the reliability of the data is unknown (Gerhart et al. 2000).

Perhaps the real question about the reasonableness of these effect magnitudes is whether the regression coefficients for the HR practices from which they are derived are excessively large. To evaluate this question, I translated the coefficients from Model 1 in Table 4 into percentage changes in value added. For the standardized HR practice variables, this transformation is achieved by the expression $100\left(e^{\beta}-1\right)$ and shows that a one standard deviation increase in self-managed teams, job rotation, and average pay is associated with a change in value added of, respectively, $15 \%,-7.7 \%$, and $25.9 \%$. However, note that a one standard deviation increase in these HR practices is considerable in practical terms. For self-managed teams, this increase means the participation of $29 \%$ more workers; for job rotation, $31 \%$ more workers. A one standard deviation increase in training expense implies an additional $\$ 418,000$ spent on training, compared to establishments at the mean level of training expense. In this light, the coefficients for the HR practice variables seem to be of reasonable magnitudes.

Additionally, note that the change in adjusted $\mathbf{R}^{2}$ from adding the HR practices to the controls model ranges from 0.02 to 0.03 . While this is certainly not trivial in practical terms given the scale of the dependent variable, the relative amount of adjusted $\mathbf{R}^{2}$ that is added by the HR practice variables versus the control variables is comparable to previous SHRM results in manufacturing settings. For example, Youndt et al. (1996) found a change in adjusted $R^{2}$ of 0.06 when their HR system variables were added to their controls models, while Dunlop and Weil (1996) found an increase of 0.10 in adjusted $R^{2}$ after adding a production/HR system variable when predicting operating profit as a percentage of sales. Similarly, MacDuffie (1985) found increases in adjusted $\mathrm{R}^{2}$ ranging from 0.02 to 0.06 when he added different individual work organization and HR scales to his controls model.

Finally, I note that Huselid (1995) esti- 
mated that a one standard deviation increase in his measure of an HR system was associated with $\$ 27,044$ higher sales per employee. For a firm with the mean number of employees in his sample $(4,413)$, Huselid's estimate suggests an increase of over $\$ 119$ million in sales. While Huselid's sample was not confined to manufacturing and was at the firm level rather than the establishment level, his results suggest that the magnitudes of effects estimated in this paper are not unreasonably large.

\section{Discussion}

The results support the general contention that substantial departures from linearity can occur in the relationships between HR practices and establishment performance. In this study, four of six HR practice variables exhibit statistically significant non-linearity in their estimated relationships with log of value added. There are different degrees of support for the hypotheses, however. As depicted in Figure 1, this paper's two complementary hypotheses suggest a curve with two inflection points, an upward inflection in the first part of the curve (consistent with Hypothesis 1) and a downward inflection in the latter part of the curve (consistent with Hypothesis 2). However, the polynomial analysis in Table 4 only identified the curve for one variable, quality meetings, as having two inflection points of this kind. Job rotation also has two inflection points, but the upward inflection occurs after the point of decreasing returns, contrary to expectations. Theoretically, it is unclear why this latter upward inflection occurs, as it is not consistent with the scale effects of implementation logic. The quadratic term for formal training expense also indicates an upward inflection consistent with Hypothesis 1 , but no point of decreasing returns within its observed range.

On the other hand, the results indicate that three of the six HR practices-quality meetings, job rotation, and average payhave curves at least partially consistent with Hypothesis 2, decreasing marginal returns. Perhaps, as noted in the discussion preceding Hypothesis 2 above, these decreasing returns come from differential selection into qual- ity meetings and job rotation, with workers who can most benefit establishments being assigned to quality meetings and job rotation first. However, it is unclear why such differential selection into an HR practice does not also give the self-managed teams variable a point of decreasing returns, and the decreasing returns to average pay probably operate through a different mechanism, because average pay does not seem amenable to decreasing returns.

Nevertheless, two of the three HR variables that are measured in ways that could capture differential selection show points of decreasing returns, while the two HR variables that are measured in ways that could capture different intensities with which an HR practice occurs across establishments do not show decreasing returns within the observed range of the dependent variable. On the other hand, Hypothesis 1 is unambiguously supported by one of these latter two HR practice variables, training expense. Although preliminary and limited in scope, these results imply that non-linearity in SHRM works in different ways, but perhaps in more complex forms than I hypothesized in this paper. This is an issue worthy of further examination in future research, as only a few HR variables measured in each way are available in these data.

Further, the results for the HR index suggest that appreciable non-linearities in SHRM research can be masked by aggregation, a finding that underscores the importance of comparing results for $\mathrm{HR}$ indices with results for the indices' separate component variables. In future research, it will be important to examine non-linearities in contexts where data and theory support a more robust aggregated measure of HR practices than the one that I employed here (for example, MacDuffie 1995).

Additionally, the results for the subsamples imply that industry-based heterogeneity is not particularly important as a cause of nonlinearities within this sample. Indeed, the two $H R$ variables that, by construction, are least likely to show nonlinearities via the mechanisms spelled out in the hypotheses, average pay and the HR index, are also the variables with results that changed substan- 
tively across the subsamples.

Overall, these results are a reminder that, just as aggregation can mask important nuances by oversimplifying a causal relationship, the search for linearity in organizational research may miss information that is important to accurately describing causal relationships. As Table 7 demonstrates, assuming linearity in the relationship between HR practices and organizational performance may be fairly precise through the middle range of the HR practice variables' values but may lead to increasing inaccuracy at the endpoints of some of the HR practice variables' distributions. Yet, what happens at the lowest and highest levels of HR practice implementation may be more theoretically important in understanding causality than these relationships' middle ranges.

Although compelling, these initial findings are not without limitations. The manufacturing sector lent itself to this study because the HR practice and control variables employed here could be drawn from previous research and because straight-line relationships between HR system measures and various organizational performance variables in manufacturing had been established. However, because production efficiencies in manufacturing are the product of interrelationships between human and physical capital (Koch and McGrath 1996), points of decreasing returns to investments in HR practices are dictated by the limits of physical capital as well as by the limitations of human beings, work organization, and the like, perhaps making it more likely that decreasing returns will be observed in this setting. Accordingly, it would be instructive to study non-linearities in industries outside of manufacturing in future research.

A bigger issue is the limited set of $\mathrm{HR}$ practice variables available for study in these data. As I noted above, concern about omitted HR practice variables is common to SHRM research because of the difficulties in gathering such data. This issue is especially important if omitted $\mathrm{HR}$ practices are highly correlated with the HR practices and with the dependent variable used in the analysis, because such omissions bias the results. However, I note again that the six HR practices examined in this paper are representative of practices emphasized in lean manufacturing and high performance work system models. Thus, high intercorrelations among these HR practice variables would not be surprising. Because such correlations are not particularly strong among the observed HR practice variables, it is possible that correlations with omitted HR practice variables connected with the lean manufacturing/high performance work system concept are also low and the omitted variable biases are therefore not large. Further studies of non-linearity in SHRM could be enhanced by using different dependent variables, such as turnover, as well. Additionally, it may be important to explore, rather than simply control for, the effects of organizational heterogeneity, such as establishment strategies and establishment size, on non-linearities in the HRM $\rightarrow$ organizational performance relationship.

It is also important to note the relatively small size of the non-linearities identified here versus the effects of the control variables, which dwarf the effects of the HR practice variables. Nevertheless, as the above section on magnitudes of effects detailed, these non-linearities are still quite meaningful substantively. Moreover, the overall effects of the HR practices are consistent with those found in other SHRM research in manufacturing, and a robust set of controls is crucial to allaying concerns that the non-linearities found here are artifacts of incomplete modeling. Further, one would reasonably expect the control variables I use to have stronger relationships with value added than the HR practices, particularly in manufacturing. However, the contrast in effects sizes warrants more notice than it typically receives in the sometimes expansive discussions of SHRM's importance in the literature. This might be more likely to happen if more attention were paid to interpreting point estimates of effect magnitudes in empirical SHRM research (Becker and Gerhart 1996).

In sum, modeling non-linearities accurately in SHRM research has important repercussions for researchers' substantive interpretations of the relationship between HR systems and performance. Straight-line 
estimates of such relationships may dramatically misstate the effectiveness of HR systems, and practitioners may find that the expected benefits of implementing an HR system do not materialize because such discrepancies were not anticipated. In contrast, greater atten- tion to non-linearities by SHRM researchers would likely enhance our theoretical understanding and sharpen our recommendations for managerial practice, helping to advance SHRM beyond the general notion that HR matters.

\section{REFERENCES}

Arthur, Jeffrey B. 1994. "Effects of Human Resource Systems on Manufacturing Performance and Turnover." Academy of Management Journal, Vol. 37, No. 3 (June), pp. 670-87.

Batt, Rosemary. 2002. "Managing Customer Services: Human Resource Practices, Quit Rates, and Sales Growth." Academy of Management Journal, Vol. 45, No. 3 (June), pp. 587-97.

Becker, Brian, and Barry Gerhart. 1996. "The Impact of Human Resource Management on Organizational Performance: Progress and Prospects." Academy of Management Journal, Vol. 39, No. 4 (August), pp. 779-801.

Cappelli, Peter. 2001. "The National Employer Survey: Employer Data on Employment Practices." Industrial Relations, Vol. 40, No. 4 (October), pp. 635-47.

Cappelli, Peter, and David Neumark. 2001. "Do 'HighPerformance' Work Practices Improve EstablishmentLevel Outcomes?" Industrial and Labor Relations Review, Vol. 54, No. 4 (July), pp. 737-75.

Dean, James W., and Scott A. Snell. 1996. "The Strategic Use of Integrated Manufacturing: An Empirical Examination." Strategic Management Journal, Vol. 17, No. 6, pp. 459-80.

Delaney, John T., and Mark A. Huselid. 1996. "The Impact of Human Resource Management Practices on Perceptions of Organizational Performance." Academy of Management Journal, Vol. 39, No. 4 (August), pp. 949-69.

Delery, John E. 1998. "Issues of Fit in Strategic Human Resource Management: Implications for Research.” Human Resource Management Review, Vol. 8, No. 3, pp. 289-309.

Dunlop, John T., and David Weil. 1996. "Diffusion and Performance of Modular Production in the U.S. Apparel Industry." Industrial Relations, Vol. 35, No. 3 (July), pp. 334-55.

Dyer, Lee, and Todd Reeves. 1995. "Human Resource Strategies and Firm Performance: What Do We Know and Where Do We Need to Go?" International Journal of Human Resource Management, Vol. 6, No. 3 (September), pp. 656-70.

Gerhart, Barry, Patrick M. Wright, Gary C. McMahan, and Scott A. Snell. 2000. "Measurement Error in Research on Human Resources and Firm Performance: How Much Error Is There and How Does It Influence Effect Size Estimates?” Personnel Psychology, Vol. 53, No. 4 (Winter), pp. 803-34.

Guthrie, James P. 2001. "High-Involvement Work Prac- tices, Turnover, and Productivity: Evidence from New Zealand." Academy of Management Journal, Vol. 44, No. 1 (February), pp. 180-90.

Heckman, James J. 1979. "Sample Selection Bias as a Specification Error." Econometrica, Vol. 47, No. 1 (January), pp. 153-61.

Hitt, Michael A., Leonard Bierman, Shimizu Katsuhiko, and Rahul Kochhar. 2001. "Direct and Moderating Effects of Human Capital on Strategy and Performance in Professional Service Firms: A Resource-Based Perspective." Academy of Management Journal, Vol. 44, No. 1 (February), pp. 13-28.

Huselid, Mark A. 1995. "The Impact of Human Resource Management Practices on Turnover, Productivity, and Corporate Financial Performance." Academy of Management Journal, Vol. 38, No. 3 (June), pp. 635-72.

Huselid, Mark A., and Brian E. Becker. 1995. "The Strategic Impact of High Performance Work Systems.” Working paper, Rutgers University.

Huselid, Mark A., Susan E. Jackson, and Randall S. Schuler. 1997. "Technical and Strategic Human Resource Management Effectiveness as Determinants of Firm Performance." Academy of Management Journal, Vol. 40, No. 1 (February), pp. 171-88.

Ichniowski, Casey, Karhryn Shaw, and Giovanna Prennushi. 1997. "The Effects of Human Resource Management Practices on Productivity: A Study of Steel Finishing Lines." American Economic Review, Vol. 87, No. 3 (June), pp. 291-313.

Koch, Marianne J., and Rita Gunther McGrath. 1996. "Improving Labor Productivity: Human Resource Management Policies Do Matter." Strategic Management Journal, Vol. 17, No. 5, pp. 335-54.

Lam, Long W., and Louis P. White. 1998. "Human Resource Orientation and Corporate Performance." Human Resource Development Quarterly, Vol. 9, No. 4 (Winter), pp. 351-64.

Lee, Jangwoo, and Danny Miller. 1999. "People Matter: Commitment to Employees, Strategy, and Performance in Korean Firms." Strategic Management Journal, Vol. 20, No. 6 (June), pp. 579-93.

MacDuffie, John Paul. 1995. "Human Resource Bundles and Manufacturing Performance: Organizational Logic and Production Systems in the World Auto Industry." Industrial and Labor Relations Review, Vol. 48, No. 2 (January), pp. 197-221.

Pritchard, Robert D., and Patricia Galgay Roth. 1991. "Accounting for Nonlinear Utility Functions in Com- 
posite Measures of Productivity and Performance." Organizational Behavior and Human Decision Processes, Vol. 50, No. 2 (December), pp. 341-59.

Schafer, Joseph L. 1997. Analysis of Incomplete Multivariate Data. New York: Chapman \& Hall.

Schmidt, Frank L., and John E. Hunter. 1998. "The Validity and Utility of Selection Methods in Personnel Psychology: Practical and Theoretical Implications of 85 Years of Research Findings." Psychological Bulletin, Vol. 124, No. 2 (September), pp. 262-74.
Wright, Patrick M., Blaine McCormick, W. Scott Sherman, and Gary C. McMahan. 1999. "The Role of Human Resource Practices in Petro-Chemical Refinery Performance." International Journal of Human Resource Management, Vol. 10, No. 4 (August), pp. 551-71.

Youndt, Mark A., Scott A. Snell, James W. Dean, and David P. Lepak. 1996. "Human Resource Management, Manufacturing Strategy, and Firm Performance." Academy of Management Journal, Vol. 39, No. 4 (August), pp. 836-66. 